\title{
A LARGE LEFT ATRIAL MYXOMA - A CASE REPORT
}

\author{
Naba Kumar Pattnaik ${ }^{1}$, Prasanna Kumar Mishra ${ }^{2}$ \\ ${ }^{1}$ Consultant, Department of Cardiothoracic Surgery, Apollo Hospital, Bhubaneswar, Odisha. \\ ${ }^{2}$ Consultant, Department of Anaesthesiology, Apollo Hospital, Bhubaneswar, Odisha.
}

\section{ABSTRACT}

\section{BACKGROUND}

Atrial myxomas are the most common primary cardiac tumours. More than $90 \%$ of cases are solitary. A large myxoma occupying in the left atrium producing features of mitral stenosis and regurgitation was demonstrated by 2D echocardiographic images in this case. It remained asymptomatic for a long period with survival up to 60 years in an elderly man.

\section{KEYWORDS}

Myxoma, Left Atrial, Mitral Valve Obstruction, 2D Echocardiography.

HOW TO CITE THIS ARTICLE: Pattnaik NK, Mishra PK. A large left atrial myxoma - A case report. J. Evolution Med. Dent. Sci. 2016;5(98):7213-7215, DOI: 10.14260/jemds/2016/1631

\section{BACKGROUND}

Primary intracardiac tumours are rare. About $75 \%$ of cases are benign, out of which approximately $50 \%$ are myxomas, which have an incidence of $0.0017 \%$ in general population. Histologically, myxomas are real tumours derived from multipotent mesenchymal cells of the subendocardium. ${ }^{1}$ The most frequent benign tumours of the heart are myxomas accounting for about $30 \%$ of all primary cardiac tumours, ${ }^{2}$ $75 \%$ are located in left atrium. ${ }^{3}$

Myxoma is a benign neoplasm originating from endocardial cell in the region of fossa ovalis and is attached to intra-atrial septum. They are pedunculated, friable, soft, gelatinous, mucoid and usually a grey white mass with areas of haemorrhage. They grow slowly and produce symptoms when they enlarge in size. Myxomas may be smooth surfaced and more often irregular in shape or have the appearance of "cluster of grapes". It can be large enough, occupying most of left atrium and result in obstructing left ventricular filling.

The diagnosis can be well established by demonstrating a mass in left atrium by 2D Echocardiography.4,5 Although asymptomatic atrial myxoma in patients has been reported, most of the patients present with one or more effect of a triad of, constitutional, embolic, and obstructive manifestation. ${ }^{6}$

These large pedunculated tumours advance through and obstruct the atrioventricular valve during diastole and are expelled retrogradely into atrium during systole. The most common clinical presentation mimics that of mitral valve disease. ${ }^{7}$ The differential diagnosis is mainly between rhabdomyoma, thrombus, metabolic carcinoma and melanoma. 8,9

\section{CASE REPORT}

A 60-year-old man was admitted with history of exertional dyspnoea and palpitation for a period of last 6 months. The patient was symptomatic in the early morning hour while getting up from bed and gets relieved when lying down.

Financial or Other, Competing Interest: None.

Submission 29-10-2016, Peer Review 24-11-2016,

Acceptance 01-12-2016, Published 08-12-2016.

Corresponding Author:

Dr. Naba Kumar Pattnaik,

Plot No. 1211/C, Sector-6 CDA,

Bidanasi, Cuttack-753014.

E-mail:drnkpattnaik.ctvs@gmail.com

DOI: $10.14260 /$ jemds/2016/1631
The symptoms were intermittent for a short period. $\mathrm{He}$ was having constitutional symptoms of arthralgia, myalgia, and weight loss. On preliminary examination, he was of thin built, Pulse 118/min., irregular. BP was 148/94 mmHg.

Physical examination revealed mild clubbing, auscultatory findings were consistent with mitral valve stenosis and incompetence. A loud first heart sound, low pitch "tumour plop", a hollow systolic murmur that was loudest at the apex and a mid-diastolic murmur was well noticed in sitting position. These findings resembled rheumatic mitral stenosis and regurgitation.

ECG revealed atrial fibrillation (AF). There was left atrial enlargement in X-ray chest (Figure 1). 2 D Echocardiography showed LA Diameter of $5.3 \mathrm{~cm}, \mathrm{EF}$ of $60 \%$ and there was a large LA mass occupying the left atrium measuring $4.5 \times 2.6$ $\mathrm{cm}$, protruding into Left Ventricle (LV) with normal LV systolic function (Figure 2).

Considering his age, coronary angiogram was done and found to be normal. As the LA mass was producing symptoms as described, he was advised to undergo surgical intervention under cardio pulmonary bypass (CPB).

The results of routine investigation prior to surgery was as follows. Hb 10.2 g\%, TLC 9500, Platelet count 1.76 Lakhs, INR 1.2, FBS $100 \mathrm{mg} \%$, Urea 32, Creatinine 0.9, Na 132, K 3.8. Four units of fresh blood was kept ready for surgery.

During General Anaesthesia, all vitals, EKG, SpO2, Invasive Blood pressure, CVP, Temperature, Urine output were monitored. A midline sternotomy was done. Cardiopulmonary bypass was established with aortic and bicaval cannulation and moderate hypothermia was used. Myocardial protection was achieved by cold antegrade cardioplegia. Care was taken to avoid manipulation and the aorta was cross clamped to avoid fragmentation or embolisation of the LA mass. The surgical approach was through LA atrium. On opening the LA, a big mass of $5.5 \times 4.5 \times 6.0 \mathrm{~cm}$, lobulated, irregular, greyish, gelatinous with elastic constituency was found. (Figure 3,4 ). The mass was arising from the free wall of the left atrium at the pulmonary venous confluence and protruding into the left ventricle.

The mass was removed in toto taking care not to break into smaller segments and was sent for histopathological study. The base of the mass from where it was arising was fulgurated with electrocautery to prevent haemorrhage and recurrence. The patient came off the bypass well and recovery was uneventful. 
Histopathological examination of the mass revealed, abundant myxoid stroma with stellate cells. Necrosis, mitotic activity, atypia and pleomorphism was not detected (Figure 5). This confirms diagnosis of myxoma.

The patient was discharged on $8^{\text {th }}$ day and was followed up regularly without any symptoms.

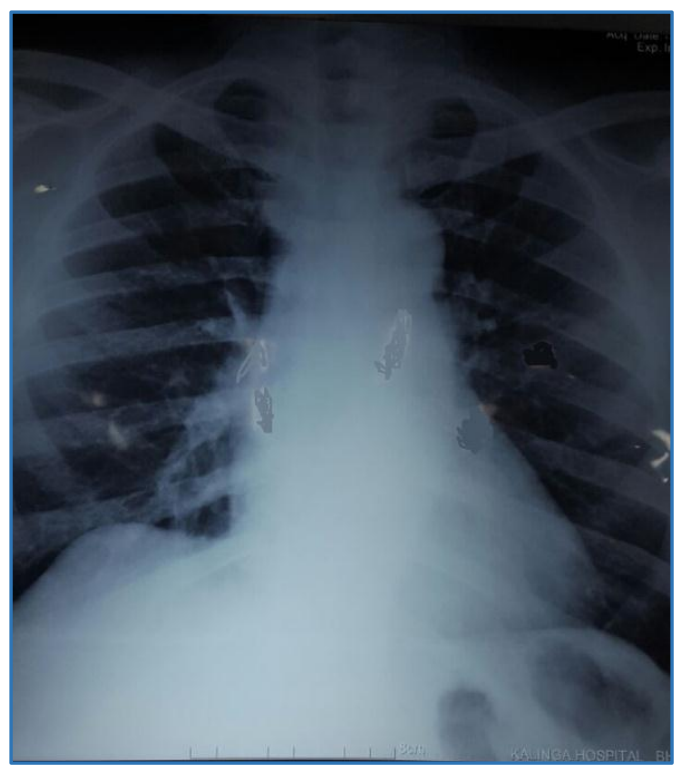

Figure 1: Chest X-ray showing LA Enlargement

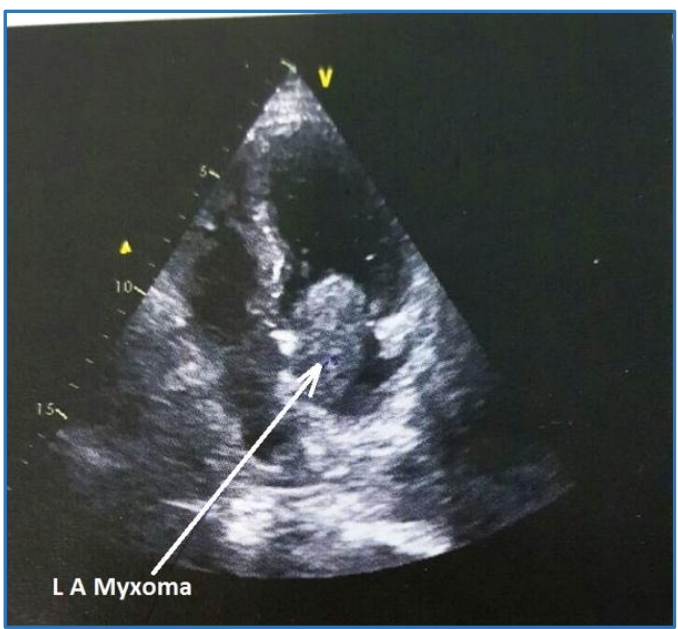

Figure 2. 2D Echo showing large LA Mass Protruding into $\mathrm{LV}$

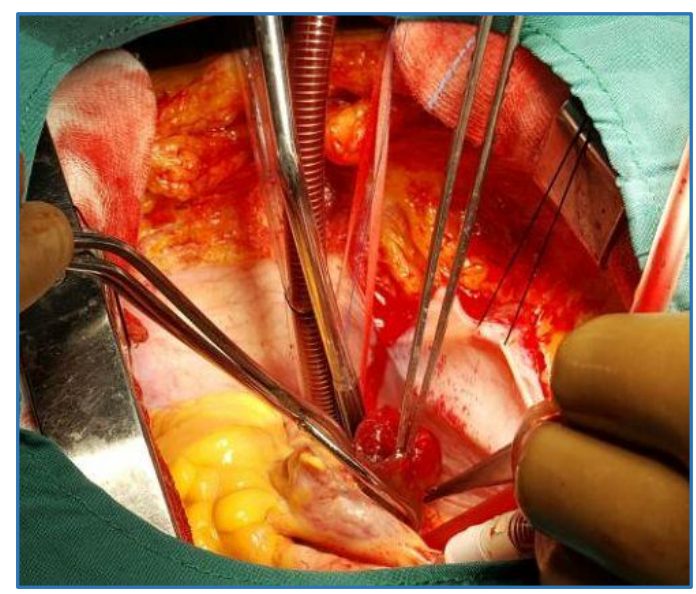

Figure 3. Operative Field showing LA Mass being Delivered

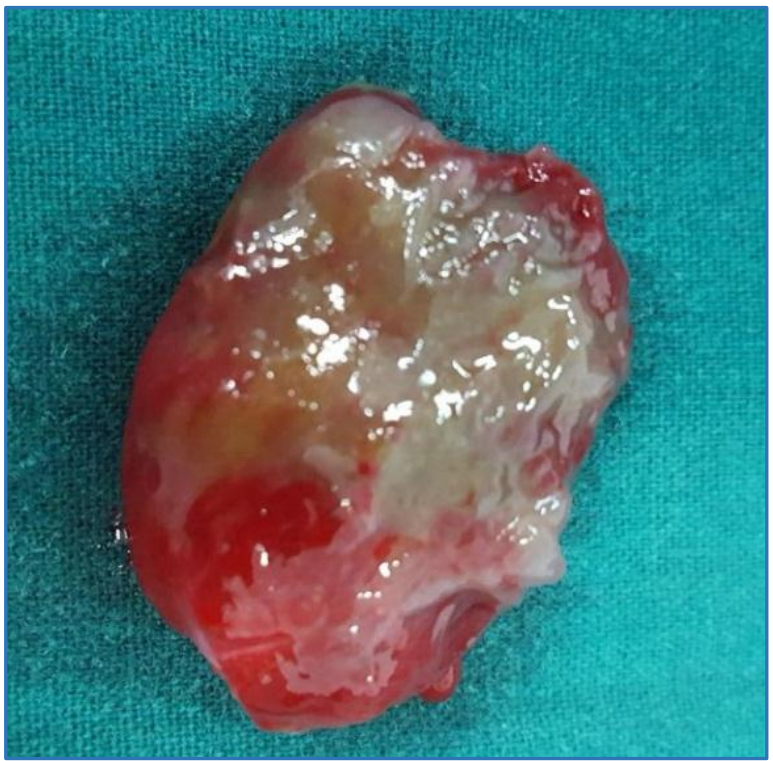

Figure 4. Large LA Mass (Being Removed)

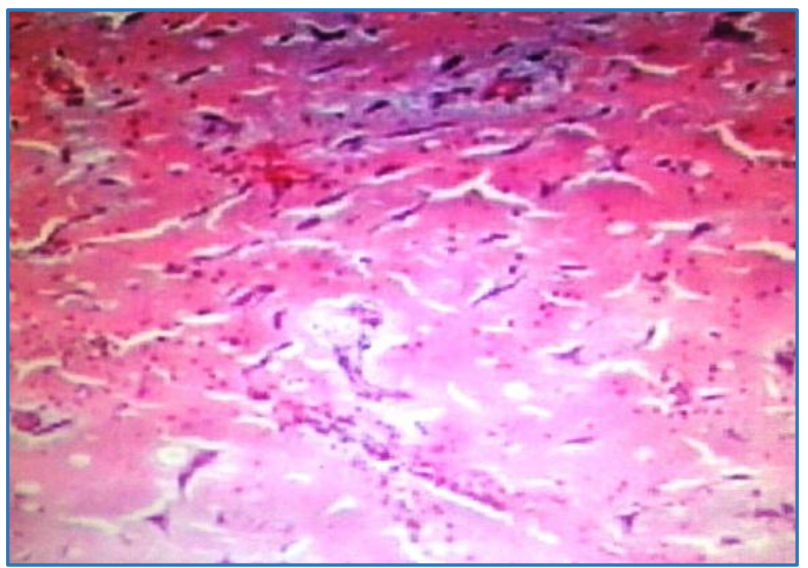

Figure 5. Histopathology showing Abundant Myxoid Stroma

\section{DISCUSSION}

The most common primary cardiac tumour arising in left atrium is the benign myxoma with large majority of cases solitary. ${ }^{10}$ In a large single institutional series of primary cardiac tumours, $42 \%$ are cardiac myxoma. ${ }^{11}$ Proportion of myxoma in comparison of other cardiac tumours was increased to $77 \%$. The mean age of presentation with sporadic myxoma is 56 years. The association of constitutional symptoms is likely due to synthesis and secretion of interleukin-6. Left atrial myxoma prolapsed to various degrees into mitral valve orifice resulting in obstruction to atrioventricular blood flow and frequently mitral regurgitation. The resulting sign and symptoms often mimic those of mitral valve disease. ${ }^{12}$

The symptom of sudden onset, intermittent and relation to patient's body posture should raise the suspicion of left atrial myxoma and it was so in our case. When atrial myxoma obstructs AV valve, the patient may experience dyspnoea, dizziness or syncope when sitting or standing with alleviation of symptoms on lying down. The first heart sound which was loud in our case is due to late onset of mitral valve closure resulting from prolapse of tumour through mitral valve. In many cases, an early diastolic sound termed as "tumour plop" 
can be identified. This is thought to be produced as the tumour strikes the endothelial wall and its excursion totally abrupt.

Echocardiography is virtually diagnostic of myxoma. The ability to diagnose atrial myxoma by echocardiography was reported more than two decades ago by Effect and Doaming. 2D Echocardiography is a non-invasive procedure of choice for diagnosis of LA myxoma. The tumour tissue manifests as spherical/pedunculated mass attached to the endocardial surface with hypoechoic area. ${ }^{13}$

Myxomas are mottled in appearance and in some atrial myxomas areas of echolucency correspond to areas of haemorrhage within the tumour which are not seen in thrombi or infective lesions.

In this case 2D Echocardiography illustrates the obstructive feature masquerading as rheumatic mitral regurgitation and stenosis. Echocardiographically, the mitral valve appears normal without any suggestive finding of valve thickening, commissural fusion or calcification. The resultant mitral stenosis and regurgitation are due to movement of myxoma across the mitral valve, so they are functional and disappear after removal of the tumour.

Surgical excision is the treatment of choice for most of the benign cardiac tumours and in many cases this results in a complete cure. Recurrence is 1 to $5 \%$ after resection. Prompt excision using cardiopulmonary bypass was first carried out by Crafoord in 1954, established as the only acceptable mode for treatment of myxoma. ${ }^{14}$ In contrast to biatrial approach, the left atriotomy approach is considered to be adequate and has demonstrated the low recurrence rate and safety of the technique. ${ }^{15}$

\section{CONCLUSIONS}

A large myxoma occupying the left atrium remaining asymptomatic up to age of 60 years in a male is a rare presentation in tropical country like India and in coastal region of Odisha.

\section{REFERENCES}

1. Valemde P, Sabrinho FA, Sales MV, et al. Giant myxoma in the left atrium: case report. Rev Bras Cir Cardiovas 2008;23(2):276-8.
2. Reynen K. Frequency of primary tumour of the heart. Am J Cardiology 1996;77(1):107.

3. Reynen K. Cardiac myxomas. New Eng J of Medicine 1995;333(24):1610-7.

4. Finogan RE, Harrison DC. Diagnosis of left atrial myxoma by echocardiography. The New Eng J of Medicine 1970;282:1022-3.

5. Spencer III WH, Peter RH, Orgain ES. Detection of left atrial myxoma by echocardiography. Archives of Int Medicine 1971;128(5):787-9.

6. Talley JD, Wenger NK. Atrial myxoma: overview, recognition and management. Comprehensive therapy 1987;13(4):12-8.

7. Bass NM, Sharratt GP. Left atrial myxoma diagnosed by Echocardiography with observation on tumour movement. British Heart Journal 1973;35(12):1332-5.

8. Thakur AK, Thakur S. Infection and cardiac tumour: evaluation through imaging: medicine update. Association of Physicians of India 2003;13:575-82.

9. Jang $\mathrm{KH}$, Shin $\mathrm{DH}$, Lee $\mathrm{C}$, et al. Left atrial mass with stalk: thrombus or myxoma. J of Cardiovasc Ultrasound 2010;18(4):154-6.

10. Hanson EC. Cardiac tumour, a current perspective. New York state J of Medicine 1992;92:41.

11. Molina JE, Edward JE, Ward HB. Primary cardiac tumour: experience at the University of Minnesota. The J of Thoracic and cardio Vascular surgery 1990;38(2):183-91.

12. Salcedo EE, Cohen GI, White RD, et al. Cardiac tumour diagnosis and treatment. Current problem in Cardiology 1992;17:73.

13. Engberdig R, Daniel WG, Erbel R, et al. Diagnosis of cardiac tumour by transoesophageal echocardiography: a multicentre study in 154 patients. European cooperative study group. European Heart journal 1993;14(9):1223-8.

14. Chitwood WR. Clarence Crafoord and the first successful resection of a cardiac myxoma. Annals thoracic surgery 1992;54(5):997-8.

15. Meynes B, Vanclemmput J, Flameng W, et al. Surgery for cardiac myxoma. A 20 yrs experience with long-term follow-up. Eur J Cardio Thoracic surg 1993;7(8):437-40. 